\title{
Inhibition efficiency and corrosion rate studies of mild steel in nitric acid using 2-thioacetic acid - 5-pyridyl-1,3,4-oxadiazole complexes
}

\author{
Dina A. Najeeb \\ Department of Chemistry, College of Science, Al-Nahrain University, Baghdad, Iraq \\ E-mail: dinachem70@gmail.com
}

\begin{abstract}
The Schiff base 2-thioacetic acid-5-pyridyl-1,3,4-oxadiazole and its complexes with metal ions $\mathrm{Ni}(\mathrm{II}), \mathrm{Cu}(\mathrm{II})$ and $\mathrm{Co}(\mathrm{II})$ have been examined as corrosion inhibitors of mild steel in $1 \mathrm{~N}$ $\mathrm{HNO}_{3}$ solution by using weight loss technique. Data that we obtain shows good performance that these compounds are good inhibitors. The inhibition efficiency for the prepared ligand and its metal complexes increases with increasing their concentrations. The surface coverage values increase with increasing inhibitors concentration. The corrosion rate decreases as the concentrations of the ligand and its metal complexes increase. The inhibition efficiency of the ligand is less than that of its metal complexes and the inhibition efficiency of the metals follows the order $\mathrm{Co}>\mathrm{Ni}>\mathrm{Cu}$. In the industries the inhibitors used widely due to anti-corrosive properties, but secondary effects may be shown which damage the environment. So the researchers began to prepare environmentally friendly inhibitors, like the prepared ligand and its metal complexes. At this time, some inhibitors are not being used in industrial processes due to their toxicity of chromate, phosphate and arsenic compounds, referring to different environmental and health troubles, so the governments must impose strict international laws. Inhibition behavior of the prepared ligand and its metal complexes has been attributed to their adsorption on the steel surfaces. The adsorption of the inhibitors obeys Langmuir adsorption isotherm for all tested systems. The surface morphology of mild steel was checked using a scanning electron microscope.
\end{abstract}

Keywords: corrosion, inhibition, mild steel, nitric acid, adsorption.

Received: July 2, 2019. Published: September 6, 2019

doi: $\underline{10.17675 / 2305-6894-2019-8-3-18}$

\section{Introduction}

The problems of corrosion have gain considerable exploration because of the attack on materials. The nearly practical methods to resistance corrosion are use of inhibitors. The ability for corrosion it was reducing by adding small amounts (corrosion inhibitor) to a corrosive medium. Mild steel is an alloy of iron with carbon (carbon content $0.16-0.25 \%$ ) which suffers corrosion easily in acidic medium. Mild steel alloys extremely utilized in engineering material in movement operators, the conversion of chemical industries, refining and petroleum manufacture, marine approach, fossil fuel power plant and nuclear 
power, structure and metal processing equipments [1]. The corrosion inhibitors have a considerable practical importance for utilizing in decrease metallic waste in engineering material [2]. Some metals having the capability to form-covalent bond with metals due to their free electron pairs like N, O and S [3]. The compounds that have $\pi$-bonds show good inhibitive properties due to effect of $\pi$-orbital that interact with the surface of metal [4]. The azomethine linkage that found in the prepared ligand have effective as potential corrosion inhibitors [5,6]. Many complexes have been consider as corrosion inhibitors $[7,8]$. The inhibitor that is added to acid solution to stop the damage correspond with the metal corrosion [9]. The metal complexes and its ligand are utilized to inhibit mild steel corrosion in acid mixture [10-14]. The heterocyclic rings that have N, S, P, O etc. in their structures act as the best corrosion inhibitors of metals with considerable activity mainly in aggressive acidic medium [15-17]. This study aims to investigate the inhibitory action of a Schiff base, 2-thioacetic acid-5-pyridyl-1,3,4-oxadiazole (HL) and its metal ions complexes on mild steel corrosion in $1 \mathrm{~N} \mathrm{HNO}_{3}$ acid solutions.

\section{Experimental details}

\subsection{Material preparation}

Mild steel used in the research had the following weight percentage composition: $\mathrm{C}(0.15)$, $\mathrm{P}(0.36), \mathrm{Mn}(0.6)$ and $\mathrm{Si}(0.03)$. Each coupon was washed in ethanol, dried in acetone and kept in a desiccator.

\subsection{Electrolyte Preparation}

One molar nitric acid solution was prepared by diluting appropriate volume of $\mathrm{HNO}_{3}$ using distilled water. The concentration range of ligand and its metal complexes used was 100, 200, 300, 400 and $500 \mathrm{ppm}$ and the electrolyte used was $50 \mathrm{ml}$ for each experiment. The 2thioacetic acid-5-pyridyl-1,3,4-oxadiazole (HL) and its metal complexes were being prepared according to the procedure described previously [18]. Scheme (1) shows the preparation steps for the ligand.

\subsection{Weight loss measurement}

For weight loss measurements, circular coupons were exposed to the acidic medium $1 \mathrm{~N}$ $\mathrm{HNO}_{3} .50 \mathrm{~mL}$ of corrosive solution were put in a $100 \mathrm{ml}$ glass beaker. The coupons were immediately immersed in the test solution without and with 100, 200, 300, 400 and 500 ppm of the ligand and its metal ions complexes. After 48 hours, the coupons were taken out, washed, dried, and re-weighed. The average weight loss mild steel coupons were obtained. The IE\% and the $(\theta)$ of ligand and its metal ions complexes for mild steel corrosion were calculated using the following formula [19]:

$$
\mathrm{IE} \%=\left[W_{\mathrm{U}}-W_{\mathrm{i}} / W_{\mathrm{U}}\right] \times 100
$$




$$
\theta=\left(W_{\mathrm{U}}-W_{\mathrm{i}}\right) / W_{\mathrm{U}}
$$

Where,

IE\% = inhibition efficiency

$\theta=$ surface coverage

$W_{\mathrm{i}}=$ weight loss of mild steel in inhibited solution

$W_{\mathrm{U}}=$ weight loss of mild steel in blank solution

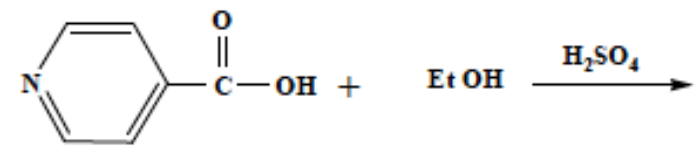

(1)

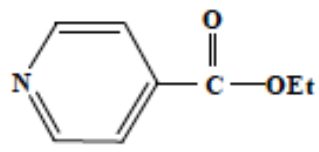

(2)

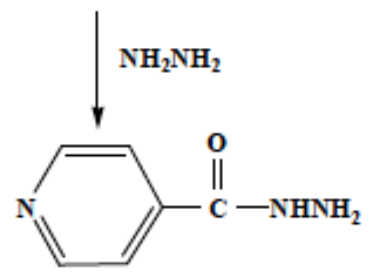

(3)

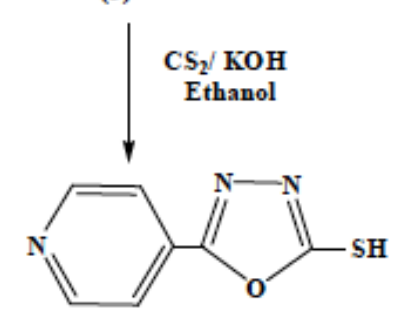

(4)

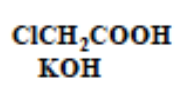

$\checkmark$

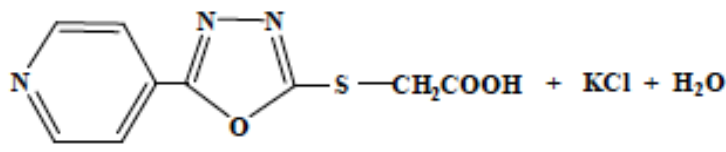

(5)

HL

Scheme 1. Reaction scheme for preparing ligand.

The corrosion rate $(\mathrm{CR})$ has been estimated from this equation [20]:

$$
\mathrm{CR}=\left(-m_{2}\right) / S \cdot t
$$

$\left(m_{1}\right)$ and $\left(m_{2}\right)$ are masses of mild steel alloy before and after corrosion respectively, $S$ is the surface area of the coupons, $t$ is immersion time. 


\subsection{Scanning Electron Microscope (SEM)}

Surface analysis of the mild steel was investigated by using SEM apparatus type JEOL SEM 5800 with a probe having accelerator voltage of $20 \mathrm{keV}$. After 48 hours of immersion in the corrosive nitric acid solution $(1 \mathrm{~N})$ without and with various concentrations $(100$, 200, 300, 400 and 500) ppm of ligand and its metal ions complexes.

\section{Results and Discussion}

\subsection{Weight loss studies}

The weight loss data, inhibition efficiency, surface coverage and (corrosion rate) of mild steel in $1 \mathrm{~N} \mathrm{HNO}_{3}$ without and with 100, 200, 300, 400 and $500 \mathrm{ppm}$ concentrations of (HL) and its metal complexes were respectively, tabulated in Tables 1 and 2. The data presented in Tables 1 and 2 show that the inhibition efficiencies increase with increasing inhibitors concentration. Similarly, surface coverage values increases with increasing inhibitors concentration due to the effect of adsorption of inhibitor molecules on the mild steel surface. The corrosion rate values decrease with increasing the concentrations of the prepared ligand and its metal complexes. Tables 1 and 2 data show that the ligand and its metal complexes behaves as a good corrosion inhibitors for mild steel alloy in $1 \mathrm{~N} \mathrm{HNO}_{3}$ solution at all concentrations. The prepared Schiff base has inhibition efficiencies towards mild steel alloy and this behavior may be assign to coordination by the (donor-acceptor) reaction between the unshared electron pairs of donor atoms of the ligand and its complexes [21]. Maximum inhabitation efficiency (89.719\%) is obtained for 48 hours immersion of mild steel in $1 \mathrm{~N} \mathrm{HNO}_{3}$ solution containing 500 ppm of $\mathrm{Co}$ (II) complex.

Table 1. Weight loss, inhibition efficiency, surface coverage and corrosion rate data of mild steel corrosion at $48 \mathrm{hrs}$. Immersion in $1 \mathrm{~N} \mathrm{HNO}_{3}$ with different concentrations of prepared ligand.

\begin{tabular}{ccccc}
\hline $\begin{array}{c}\text { Concentration } \\
\mathbf{p p m}\end{array}$ & $\begin{array}{c}\text { Weight } \\
\text { Loss }(\mathbf{m g})\end{array}$ & $\begin{array}{c}\text { Inhibition } \\
\text { efficiency }\end{array}$ & $\begin{array}{c}\text { Surface } \\
\text { Coverage }\end{array}$ & $\begin{array}{c}\text { Corrosion rate } \\
\left(\mathbf{m g} / \mathbf{c m}^{2} \cdot \mathbf{h}\right)\end{array}$ \\
\hline Blank & 321 & - & - & 1.362 \\
100 & 132 & 58.878 & 0.5887 & 0.560 \\
200 & 119 & 62.928 & 0.6292 & 0.504 \\
300 & 102 & 68.224 & 0.8622 & 0.432 \\
400 & 96 & 70.093 & 0.700 & 0.407 \\
500 & 81 & 74.766 & 0.747 & 0.343 \\
\hline
\end{tabular}


Table 2. Weight loss, inhibition efficiency, surface coverage and corrosion rate data of mild steel corrosion at $48 \mathrm{hrs}$. Immersion in $1 \mathrm{~N} \mathrm{HNO}_{3}$ containing different concentrations of $\mathrm{Co}(\mathrm{II}), \mathrm{Ni}(\mathrm{II})$ and $\mathrm{Cu}(\mathrm{II})$ complexes.

\begin{tabular}{|c|c|c|c|c|}
\hline $\begin{array}{c}\text { Concentration } \\
\text { ppm }\end{array}$ & $\begin{array}{l}\text { Weight } \\
\text { Loss (mg) }\end{array}$ & $\begin{array}{l}\text { Inhibition } \\
\text { efficiency }\end{array}$ & $\begin{array}{l}\text { Surface } \\
\text { Coverage }\end{array}$ & $\begin{array}{c}\text { Corrosion rate } \\
\left(\mathrm{mg} / \mathrm{cm}^{2} \cdot \mathbf{h}\right)\end{array}$ \\
\hline \multicolumn{5}{|c|}{ Co(II) complex } \\
\hline Blank & 321 & - & - & 1.362 \\
\hline 100 & 75 & 76.635 & 0.766 & 0.318 \\
\hline 200 & 69 & 78.500 & 0.785 & 0.292 \\
\hline 300 & 54 & 83.177 & 0.831 & 0.229 \\
\hline 400 & 47 & 85.358 & 0.853 & 0.199 \\
\hline 500 & 33 & 89.719 & 0.897 & 0.140 \\
\hline \multicolumn{5}{|c|}{$\mathrm{Ni}(\mathrm{II})$ complex } \\
\hline 100 & 95 & 70.400 & 0.704 & 0.403 \\
\hline 200 & 86 & 73.208 & 0.732 & 0.364 \\
\hline 300 & 75 & 76.635 & 0.766 & 0.318 \\
\hline 400 & 63 & 80.373 & 0.803 & 0.267 \\
\hline 500 & 52 & 83.800 & 0.830 & 0.220 \\
\hline \multicolumn{5}{|c|}{$\mathrm{Cu}(\mathrm{II})$ complex } \\
\hline 100 & 102 & 68.224 & 0.682 & 0.432 \\
\hline 200 & 92 & 71.339 & 0.713 & 0.390 \\
\hline 300 & 84 & 73.831 & 0.738 & 0.356 \\
\hline 400 & 70 & 78.193 & 0.781 & 0.297 \\
\hline 500 & 62 & 80.685 & 0.806 & 0.263 \\
\hline
\end{tabular}

The variation of inhibition efficiencies of mild steel corrosion in $1 \mathrm{~N} \mathrm{HNO}_{3}$ solution in the presence of ligand and its transition metal complexes at different concentrations is shown in Figure 1.

Figure 1 shows that the inhibition efficiency of the metal complexes is greater than that of the free ligand due to their huge size and molecular planarity [22]. Thus, the order of efficiency is as $(\mathrm{CoL})>(\mathrm{NiL})>(\mathrm{CuL})>\mathrm{L}$. 


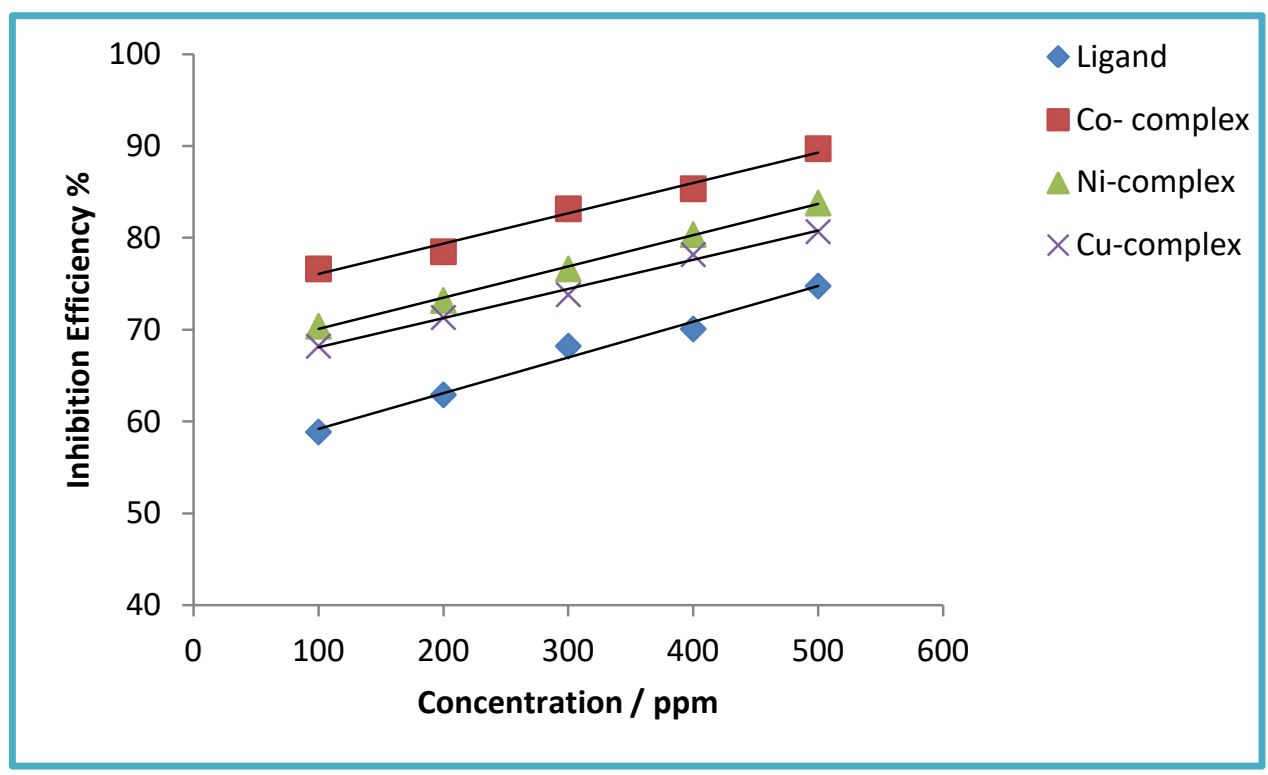

Figure 1. IE\% against concentration of the prepared ligand and its metal complexes for mild steel corrosion in $1 \mathrm{~N} \mathrm{HNO}_{3}$ solution.

\subsection{Adsorption isotherm}

Langmuir isotherm found that all the adsorption sites are equal in value, and that atom bounding take place independently from nearby sites being cover or not. Under these conditions, surface coverage $(\theta)$ proportion to bulk concentration $(C)$ of the adsorbing compound is as follows [23].

$$
K_{\text {ads }} C=\theta /(1-\theta)
$$

The $K_{\text {ads }}$ is the adsorption (equilibrium constant) and $C$ is the concentration of the inhibitors. $K_{\text {ads }}$ values were obtained from the intercepts of the linear regressions between $C / \theta$ versus $C$ for various inhibitors concentrations in the range from 100 to $500 \mathrm{ppm}$ are shown in Figure 2 and the adsorption data are listed in Table 3.

The correlation coefficients data presented in Table 3 are very close to one which confirms that the adsorption of the inhibitor molecules in $1 \mathrm{~N} \mathrm{HNO}_{3}$ solution follows Langmuir adsorption isotherm.

$K_{\text {ads }}$ data was concerning to the standard free energy of adsorption, $\Delta G_{\text {ads }}^{0}$ according to the following equation [23]:

$$
K_{\text {ads }}=(1 / 55.5) \exp \left[\left(-\Delta G_{\text {ads }}^{0}\right) / R T\right]
$$

The term $R$ referred to gas constant, $T$ is the absolute temperature in Kelvin and 55.5 is constant which clarify the concentration of water in solution in $\mathrm{mol} / \mathrm{dm}^{3}$. 


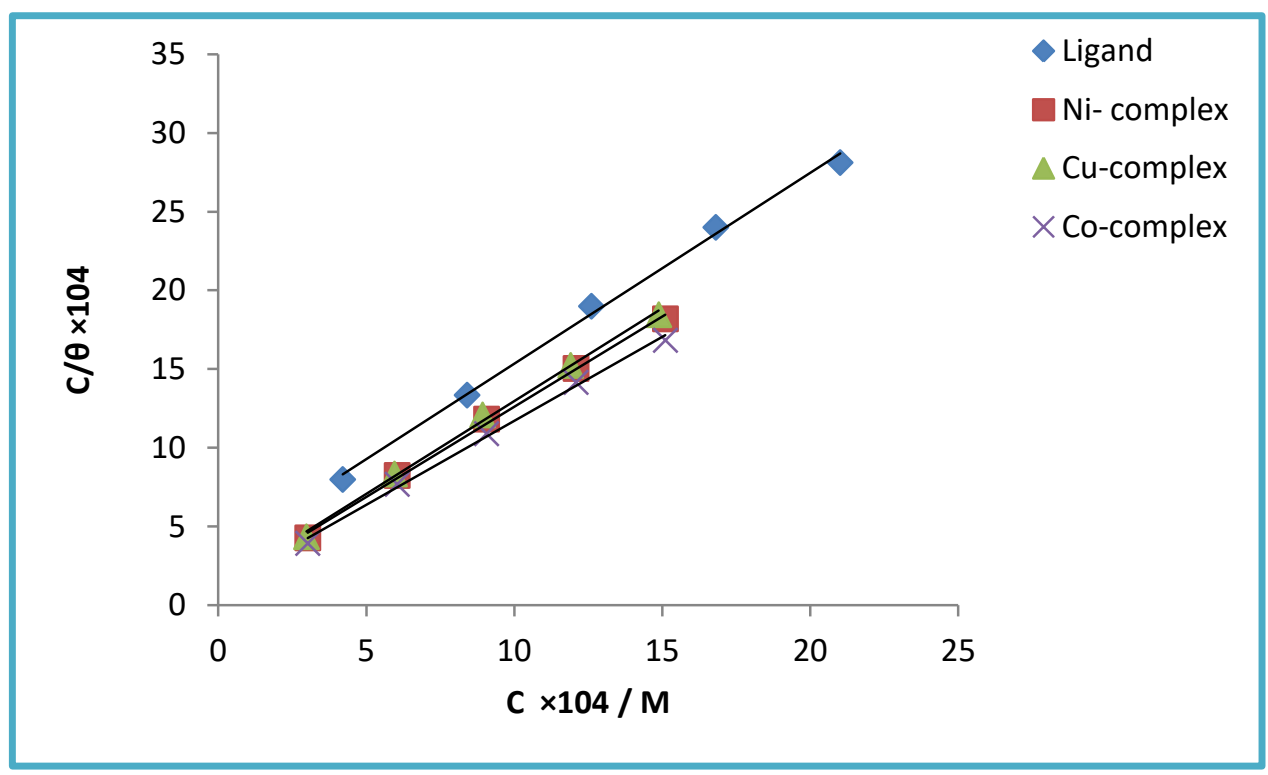

Figure 2. Langmuir isotherm plots for adsorption of the prepared ligand (HL) and its metal complexes on mild steel surface in $1 \mathrm{~N} \mathrm{HNO}_{3}$ solution.

Table 3. Thermodynamic quantities for adsorption of ligand and its metal ions complexes on mild steel.

\begin{tabular}{cccc}
\hline Inhibitors & $\boldsymbol{R}^{\mathbf{2}}$ & $\boldsymbol{K}_{\mathrm{ads}}\left(\mathbf{1 0}^{\mathbf{4}} \mathbf{M}^{\mathbf{- 1}}\right)$ & $-\Delta \boldsymbol{G}\left(\mathbf{k J} \mathbf{~ m o l}^{\mathbf{- 1}}\right)$ \\
\hline Ligand & 0.9994 & 4.241 & 30.650 \\
Co-complex & 0.9997 & 9.686 & 32.691 \\
Cu-complex & 0.9997 & 8.465 & 32.357 \\
Ni-complex & 0.9997 & 8.755 & 32.441 \\
\hline
\end{tabular}

The average value of $\Delta G_{\text {ads }}$ is $-32.03 \mathrm{~kJ} \cdot \mathrm{mol}^{-1}$. The values of $\Delta G_{\text {ads }}$ which have negative sign refers to the spontaneity of the adsorption method and stability of the adsorbed layer on the external metal surface. Researchers propose that the range of $\Delta G_{\text {ads }}$ of chemical adsorption processes for the inhibitor lies between -21 to $-42 \mathrm{~kJ} \cdot \mathrm{mol}^{-1}$ [23]. Therefore, in this present work the value of $\Delta G_{\text {ads }}$ has been suggesting within the range of chemical adsorption.

\subsection{Scanning electron microscopy (SEM)}

SEM (micrographs) gained from (unexposed) and (exposed) mild steel with $1 \mathrm{~N}^{\mathrm{HNO}_{3}}$ solution for $48 \mathrm{~h}$ at $500 \mathrm{ppm} \mathrm{Co}$ (II) complex are shown in Figure 3. It can be detect that range of harm to mild steel surface is much less, the corrosion rate could be reduced when the inhibitors is added due to protective film adsorbed on transition metal surface, which show as a barrier and was accountable for the inhibition of corrosion. 


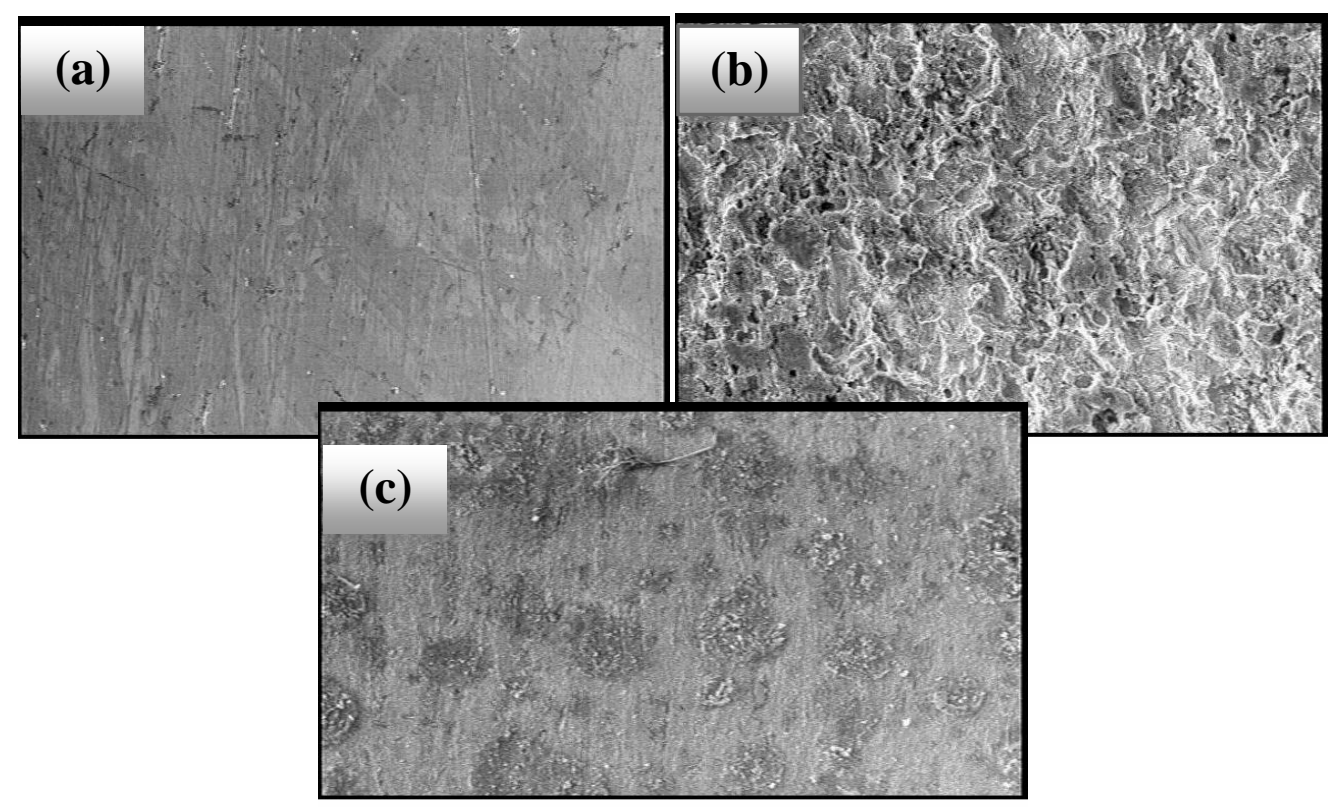

Figure 3. Scanning electron micrographs of mild steel alloy (a): unexposed polished alloy; (b): after immersion for $48 \mathrm{~h}$. In $1 \mathrm{~N}$ of $\mathrm{HNO}_{3}$ solution in absence of inhibitors (c): after immersion for $48 \mathrm{~h}$. $1 \mathrm{~N} \mathrm{HNO}_{3}$ solution in the presence of $500 \mathrm{ppm}$ of $\mathrm{Co}(\mathrm{II})$ complex.

\section{Conclusion}

The experimental weight loss results showed that the Schiff base ligand and its metal complexes are effective inhibitors for the corrosion of mild steel alloy in $1 \mathrm{~N}^{\mathrm{HNO}_{3}}$ solution. The inhibition efficiencies values reveal that, these compounds inhibit the metal oxidation in acid medium. The maximum inhibition efficiency reached $89.719 \%$ for Cocomplex which considered being the most effective inhibitor of mild steel corrosion in nitric acid solution. Langmuir adsorption isotherm gives a good explanation for the adsorption process for the ligand and its metal complexes on the mild steel surface. Gibbs free energy for adsorption data indicates that adsorption process is thermodynamically favorable and stable.

\section{References}

1. K.E. Heusler, D. Landolt and S. Trasetti, Pure Appl. Chem., 1981, 61, 1.

2. O.K. Abiola and N.C. Oforka, J. Corros. Sci. Eng., 2002, 2, no. 21, 25.

3. A. Bansiwal, P. Anthony and S.P. Mathur, Br. Corros. J., 2000, 35, 301.

4. E.E. Ebenso, P.C. Okafor, O.E. Ita, B.I. Ibok and U.J. Ekpe, Bull. Electrochem., 2001, 17, 459-464.

5. T.A. Sethi, R.K. Chaturvedi, Upadyay and S.P. Marthur, J. Chil. Chem. Soc., 2007, 52, 1206.

6. K.P. Srivastva, A. Kumar and R. Singh, J. Chem. Pharm. Res., 2010, 2, no. 6, 68.

7. M.M. Deshpande, S.B. Junne, D.V. Saraf and P.A. Kulkarni, J. Chem. Pharm. Res., 2010, 2, no. 3, 453. 
8. D.A. Najeeb and T.A. Salman, 1,2-(2,2-Dihydroxy Benzelidenamine) Phenyl Complexes as Corrosion Inhibitor for Carbon Steel in Hydrochloric Acid, J. AlNahrain University, 2018, 21, no. 3, 13-23.

9. W. Machu, In Proceedings of the Third European Symposium on Corrosion Inhibitors, University of Ferrara, Italy, 1970, 107.

10. B. El Mehdi, B. Mernari, M. Traisnel, F. Bentiss and M. Lagrenée, Mater. Chem. Phys., 2002, 77, 489.

11. F. Bentiss, C. Jama, B. Mernari, H. El Attari, L. El Kadi, M. Lebrini, M. Traisnel and M. Lagrenée, Corros. Sci., 2009, 51, 1628.

12. S.S. Abd EI-Rehim, S.A.M. Refaey, F. Taha, M.B. Saleh and R.A. Ahmed, J. Appl. Electrochem., 2001, 31, 429.

13. F. Bentiss, M. Traisnel, N. Chaibi, B. Mernari, H. Vezin and M. Lagrenée, Corros. Sci., 2002, 44, 2271.

14. M. Bouklah, A. Attayibat, S. Kertit, A. Ramdani and B. Hammouti, Appl. Surf. Sci., 2005, 242, 399.

15. E.E. Oguzie, V.O. Njoku, C.K. Enenebeaku, C.O. Akalezi and C. Obi, Corros. Sci., 2008, 50, 3480.

16. V.R. Saliyan and A.V. Adhikari, Corros. Sci., 2008, 50, 55.

17. K.C. Emregal and O. Atakol, Mater. Chem. Phys., 2003, 82, 188.

18. D.A. Najeeb, Some Transition Metal Complexes with 2-thioacetic acid-5-pyridyl1,3,4-oxadiazol, J. Al-Nahrain University, 2011, 14, no. 3, 35-39.

19. H. Ashassi-Sorkhabi, B. Shaabani and D. Seifzadesh, Appl. Surf. Sci., 2005, 239, 154.

20. M. Scendo, Corrosion inhibition of copper by purine or adenine in sulphate solutions, Corros. Sci., 2007, 49, 3953-3968.

21. P.V. Singh and A.K. Singh, Synthesis, structural and corrosion inhibition studies on cobalt(II), nickel(II), copper(II) and zinc(II) complexes with 2-acetylthiophene benzoylhydrazone, Inorg. Chim. Acta, 2011, 379, 56-63.

22. H. Shokry, M. Yuasa, I. Sekine, R.M. Issa, H.Y. El-Baradie and G.K. Gomma, Corrosion inhibition of mild steel by Schiff base compounds in various aqueous Solutions, Corros. Sci., 1998, 39, 2173-2186.

23. M.G. Hosseini, S.F.L. Mertens and M.R. Arshadi, Corros. Sci., 2003, 45, 1473. 